\title{
The Role of Linked Building Data (LBD) in Aligning Augmented Reality (AR) with Sustainable Construction.
}

\author{
Kevin Luwemba Mugumya, Jing Ying Wong, Andy Chan, Chun-Chieh Yip
}

\begin{abstract}
Over the years, the construction industry has been evolving to embrace the delicate balance between buildings and a sustainable environment by optimizing resource use to create greener and more energy efficient constructions. Sustainable building design and optimization is a highly iterative and complicated process. This is mainly attributed to the complex interaction between the different heterogenous but heuristic construction processes, building systems and workflows involved in achieving this goal. Augmented Reality (AR) has rapidly emerged as a revolutionary technology that could play a key role towards improving coordination of sustainable design processes. $A R$ makes possible the real-time visualization of a threedimensional (3D) building prototype with linked design information in a real-world environment based on a two-dimensional drawing. From past research, it is evident that this technology relies heavily on a common data environment $(C D E)$ that syncs all construction processes with their related building information in one central model. However, due to the fragmented nature of the construction industry, different domain experts generate and exchange vast amounts of heterogenous information using different software tools outside a CDE. This paper therefore investigates the performance gap that exists within Malaysia's construction industry towards using linked building data (LBD) with AR to improve the lifecycle sustainability of buildings. The results of this study clearly delineate how current construction practices in Malaysia do not favor the use of AR however, stakeholder perception is positive towards adoption of workflows that link heterogenous building data to streamline $A R$ with sustainable building design and construction.
\end{abstract}

Index Terms- Augmented Reality, Building Information Modelling, Common Data Environment, Linked Data, Sustainable construction.

\section{INTRODUCTION}

The construction industry has put pressure on the sustainability equilibrium of the natural environment and must inevitably change its conventional processes of operating with little regard for the environment [18].

Revised Manuscript Received on July 22, 2019.

* Correspondence Author

Kevin Luwemba Mugumya*, Department of Civil Engineering, University of Nottingham Malaysia, 43500 Semenyih Selangor Malaysia. (E-mail: keey4kly@nottingham.edu.my)

Jing Ying Wong, Department of Civil Engineering, University of Nottingham Malaysia, 43500 Semenyih Selangor Malaysia. (E-mail: JingYing.Wong@nottingham.edu.my)

Andy Chan, Department of Civil Engineering, University of Nottingham Malaysia, 43500, Semenyih Selangor Malaysia. (E-mail: Andy.Chan@ nottingham.edu.my)

Chun-Chieh Yip, Department of Civil Engineering, University Tunku Abdul Rahman Sungai Long Campus, 43500 Kajang, Selangor, Malaysia. (E-mail: yipcc@utar.edu.my)
Delivering sustainable construction requires holistic action from all the stakeholders involved in the designing, constructing and maintaining of the built asset [19]. Global interest in more energy efficient constructions is steadily growing and requires a willingness to explore and adopt new techniques of delivering construction projects. Construction projects are fueled by a continuous flow and exchange of information between the different stakeholders [5]. It is therefore necessary to develop new sustainable design and construction techniques with foundational basis on building information flow patterns and respective visualization techniques. Building Information Modelling (BIM) has emerged as a tool that utilizes computer technology in the design, construction and operation of buildings to transform the way asset information is propagated and used along the project lifecycle. This revolutionary digital process effectively handles vast amounts of building information centrally within a three-dimensional asset model which acts as a Common Data Environment (CDE). However, due to the fragmented nature of the construction industry, different domain experts generate and exchange large amounts of heterogenous building information which originates from various sources and often processed by different software outside a Common Data Environment (CDE) [19]. Without reliable integration of such siloed information, the construction industry still remains trapped in the inefficiency loop of unsustainable construction processes characterized by resource waste and poor energy efficiency [4]. With a CDE, all information silos generated by different departments can be linked together, visualized and used as an engine to power sustainable design processes [20]. The construction industry is responsible for consumption of energy in two principle ways i.e. resource use during construction and then subsequent energy use during operation [18]. Research has already found that the former is a relatively small percentage of the total lifetime energy use of a building. This is called embodied energy. The resources used during production are within the control of the designers, builders and the material providers while energy use during operation mainly depends on the eventual user behavior [18]. Though designers have very little influence on the operational energy use of a building, adopting LBD driven approaches, creates a comprehensive basis for improved decision making during the iterative processes of optimizing building designs [18]. Current research in the AEC industry is slowly emerging towards utilizing ontological knowledge representation techniques to semantically link heterogenous building information using semantic web tools [20]. With the emergence of 
linked building data comes a problem of handling and utilizing BIG data coherently. Efficient visualization of these linked datasets greatly determines their reliability for decision making.

The main role of this paper is to delineate how adopting a CDE workflow presents unprecedented opportunities for the emergence of data visualization technologies like Augmented Reality (AR) with specific emphasis on investigating the performance gap that exists within Malaysia's construction industry towards utilizing LBD workflows to minimize construction resources and energy use of a building design whilst using AR as a visualization tool. A discussion is also presented delineating stakeholder awareness and perception towards adoption of AR with a CDE environment.

\section{A. Moving Towards a CDE for Sustainable Construction with the Aid of $A R$}

With the extraordinary wealth of building data available on construction projects, it is safe to assume that many stakeholders integrate and use this data to inform important design decisions that minimize resource use during building construction and eventual operation. A survey proves otherwise that less than $50 \%$ of construction organizations highly value integrated building data in critical decision making [20]. Achieving sustainable designs entails complex and iterative processes that often overlap and can benefit greatly from LBD driven approaches [19]. For example, to minimize air conditioning costs without compromising indoor air quality requires designers to make decisions basing on past facility management data, occupant behavior data, HVAC system architecture information, building material properties, indoor envelope configurations, building sensors etc. [20]. All this data is readily available on construction projects but more often than not existing in isolated data silos where it cannot be used heuristically to efficiently optimize building designs. Augmented Reality (AR) technology has rapidly emerged over the past few years as a revolutionary process that could play a key role towards improved coordination of sustainable design processes by visualizing and reviewing a complex 3D building design with semantically attached LBD in a real world environment based on a two-dimensional drawing [9]. This enables faster identification of design errors that come with resource wastage and increased energy costs, faster prototyping of different design options within a common real-time visual environment where several domain experts can share sustainability design knowledge explicitly [9].

\section{B. A General Overview on AR and BIM in the AEC Industry}

$\mathrm{AR}$ is the superimposition of computer-generated files such as graphics, audio or digital information onto the real world. [3]. From the first see-through head-mounted AR display developed in the 1960s by Ivan Sutherland at Harvard [1], to the Mobile Augmented Reality system developed by Golparvar [2], several augmented reality technologies have been utilized in various disciplines but not well harnessed in the AEC (Architecture Engineering Construction) industry [3]. To improve the potential of these visualization technologies in construction, industry approaches and workflows need to be model-oriented in a Common Data Environment (CDE). Until today, most of the construction companies are still stuck in the inefficiency trap of traditional design and build methods [4]. These methodologies depend on two-dimensional (2D) computer aided design (plans, elevations and cross sections) and the design is often done in isolation [21]. These 2D workflows are also characterized by uninspiring and incomprehensible presentations; drawings are perplexing and appear lackluster for those outside the industry since $3 \mathrm{D}$ renderings are not utilized to provide an interactive visualization experience leaving the client unimpressed most of the time. The weaknesses of this workflow in terms of collaboration, visualization and stakeholder engagement has undoubtedly been one of the main causes of information loss along the project pipeline which has caused escalation in project costs, delays and unsustainable designs linked with large energy use [5]. BIM being a 3D model-based workflow, breaks this inefficiency barrier by enabling better visualizations through 3D augmentation and virtual reality, 4D for projecting schedule along the project life cycle, 5D for cost planning, 6D for energy optimization and 7D for asset life cycle and facility management (FM) [6]. Such an intelligent data model is the backbone of AR and is meant to intermarry different aspects of the design, enhance stakeholder collaboration, timely planning, clash detection and better decision-making along the project pipeline [7]. With the increasingly complex nature of the AEC/FM industry, effective data visualization techniques are paramount to provide a clear and more realistic understanding of the design as many design parameters get to conflict [8]. This is specifically evident during optimization or energy efficiency of a building i.e. there exists complex interaction between different heterogenous construction processes, building systems and workflows involved in the process framework of calibrating a design to achieve the set sustainability goals. AR visualization can be used to support all stages of the project life cycle however, most of the applications of $\mathrm{AR}$ in construction are still under research with only a few currently being applied due to limitations in tracking capabilities, alignment problems and set up cost [9]. Notable applications that have been explored include heavy construction operator training [10], automated construction progress monitoring, data collection and processing in the construction phase of the project by developing a four-dimensional AR model [11], a mobile 3-dimensional model AR system for visualizing site operations during the construction phase [3], Waugh et al. [12] developed a web-based panoramic environment to document construction progress and Park et al. [13] presented a conceptual framework that integrates AR with BIM to detect construction defects and clashes.

\section{BIM and AR advancement in Malaysia's construction industry}

The implementation of BIM and its technologies has globally been slow to realize significant benefits to the construction industry [14]. Adoption has been faster in more developed countries like the United Kingdom, United States, Hong Kong etc. mainly due to the large initial investment required for the data systems, hardware, network infrastructure and software packages [15]. Locally in Malaysia, the adoption of BIM has been slow in construction projects. According to BuildingSmart Malaysia [16], the country was first introduced to $\mathrm{BIM}$ at the 2-day Infrastructure and Construction Asia's BIM and Sustainable Architecture 
Conference in 2009. Y. Bhg Dato' Seri Ir. Dr. Judin bin Abdul Karim, Director general of Public Works Department (PWD) urged the industry to embrace the technology in their deliverables. The Malaysian government then commenced its adoption of BIM with the National cancer institute in Sepang being the first construction project to implement BIM. Since then, The National Steering Committee of Building Information Modeling was established in July 2013. This was tasked at spearheading the technology transition process. Thereafter, many seminars and workshops have been hosted with distinguished speakers from all over the world. This is a move to raise awareness and improve BIM perception in Malaysia [16].

\section{Overview on AR Adoption Challenges in the AEC Industry}

Augmented Reality visualization aims to automate the construction industry however; this does not come without challenges. Bechtel Infrastructure carried out an AR trial at a Crossrail project and Custom House station and several setbacks were faced in its implementation. The custom house project utilized the technology to track the progress of installation of prefabricated super-structure components. For the Crossrail project, the technology was used to verify construction methodology and position of the critical transfer deck [17]. From both these projects it was discovered that since construction sites are dusty, dangerous and usually in remote locations, health and safety is the biggest concern since the user wearing AR gear has divided attention and in such a busy place like a site, this becomes hazardous [17]. Sites being in remote locations cannot guarantee continuous GPS signal which is fundamental to AR technology. This can be solved by storing data locally and using Bluetooth or wired connection, but this poses an issue of cost and bulk for the end-user making the system unsuitable [17]. Other setbacks that were identified in these trials include business challenges, human interface problems while wearing gloves and issues regarding level of detail. Stephen [17] highlights that other possibilities of augmentation can be explored i.e. rather than obscuring the user's view with model data, voice can be used which will be less distracting for the end user and safer on site. Compared to other industries, AR needs a different perspective to prove beneficial to the construction industry beyond just being a visual aid [15]. Aryani et al [15] presented a generalization of factors contributing to slow adoption of BIM and its technologies in Malaysia i.e. people, process and technology. From the authors' analysis, it was discovered that top-level management plays a key role in BIM implementation as they have the power to influence, facilitate and train their staff. The same study also found out that government bodies did not provide sufficient general documentation for construction key players to follow during implementation. The findings from past works indicate that BIM and its technologies (AR, VR etc.) are a step towards achieving more sustainable and energy efficient building designs with faster and cheaper methodologies [7]-[11]. However, to the best of the authors' knowledge, little effort has been made to comprehensively investigate if construction key players understand the role of LBD within a $\mathrm{CDE}$ in aligning $\mathrm{AR}$ towards improved coordination of sustainable design and optimization processes. This paper is therefore attempting to benchmark current Malaysia's construction practices to assess how far they lie from CDE requirements of using $\mathrm{LBD}$ with $\mathrm{AR}$ for sustainable construction.

\section{MeThodology}

\section{A. Research Method}

A quantitative approach was adopted for this study. Questionnaires prepared by Qualtrics were used in surveying a sample population of clients, contractors, consultants and developers in selected construction companies across Malaysia. Statistical analysis, validity and reliability checks were done using IBM's Statistical Package for Social Science (SPSS).

\section{B. Questionnaire Structure}

Semi-structured and open-ended questions were organized in sections as shown in Table I depending on the objective to be achieved.

\section{Pilot study}

Before developing any questionnaires, several construction key players in Malaysia were consulted to get their opinion on how much they had utilized BIM technologies on their projects. This was done through emails and phone calls. The results of this study showed that, questionnaires would not easily be comprehended by most key players if no background information about Augmented Reality was provided. The researcher was therefore compelled to prepare a brief recorded easy to understand graphical demonstration (audio-visual) showing Augmented Reality in action See Fig .1. This demo package was presented together with the distributed questionnaires to reduce any misunderstandings between the researcher's design intentions and respondents understanding of the problem. The questionnaires were adjusted basing on initial comments before final rollout.

\section{Ethical Consideration}

Survey questionnaires were reviewed and approved by the ethics board of University of Nottingham Malaysia to ensure confidentiality and compliance to anonymity requirements of data collection.

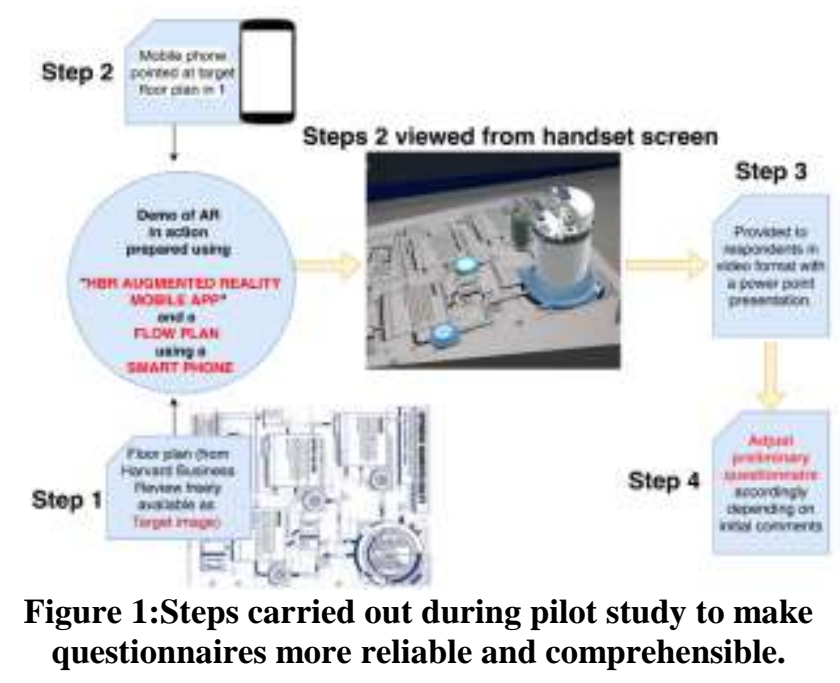

\section{E. Reliability Testing}

Cronbach Alpha test was used to test the consistency of the results. 
This test was not required for all response questions, as some were tailored by the researcher for independent analysis.

Table I: Questionnaire structure

\begin{tabular}{|l|l|}
\hline $\begin{array}{l}\text { Part A } \\
\text { Fig.2(A-C) }\end{array}$ & $\begin{array}{l}\text { Respondents' background, } \\
\text { professional experience and position } \\
\text { held in organization }\end{array}$ \\
\hline $\begin{array}{l}\text { Part B } \\
\text { Fig.2(D-L) }\end{array}$ & $\begin{array}{l}\text { Comparison of conventional 2-D } \\
\text { workflows with AR and BIM(CDE) } \\
\text { workflows. }\end{array}$ \\
\hline $\begin{array}{l}\text { Part C } \\
\text { Fig.2(M-Q) })\end{array}$ & $\begin{array}{l}\text { Stakeholder perception on } \\
\text { effectiveness of AR if deployed on } \\
\text { their projects. }\end{array}$ \\
\hline $\begin{array}{l}\text { Part D } \\
\text { Fig.2(R-V) }\end{array}$ & $\begin{array}{l}\text { Evaluation of ease of transition to this } \\
\text { technology and implementation } \\
\text { issues. }\end{array}$ \\
\hline $\begin{array}{l}\text { Part E } \\
\text { Fig.2(W) }\end{array}$ & $\begin{array}{l}\text { Open ended questions to collect } \\
\text { information on respondents' practices } \\
\text { that may be affecting adoption of CDE } \\
\text { workflows and possible solutions. }\end{array}$ \\
\hline
\end{tabular}

\section{RESUlTS}

\section{A. Part A: Demographic analysis and respondents'} background.

The surveys were tailored and targeted towards Malaysian construction stakeholders who use engineering drawings the most i.e. consultants (Engineers, CAD draftsmen, MEP designers, Land surveyors), contractors, developers, government agencies and clients. 150 questionnaires were sent out by email with 2 emails for each company and thereafter supplemented by direct visits when necessary. 63 reliable responses were acquired from 31 companies out of the total 150 with one company responding to only a single questionnaire. Selangor was chosen as the representative state due to the large number of ongoing mega-projects. Majority of the respondents were consultants and contractors with more than $50 \%$ having professional experience of 5 years or more as in Fig. 2(B). However, more than $90 \%$ of the respondents in Fig. 2(C) have less than 5 years' experience in the use of BIM as a CDE approach. It is evident that BIM exposure is very low in Malaysia's construction industry.

For this specific study, respondents' low BIM expertise and experience is leveraged by their high working experience for purposes of providing reliable responses.

\section{B. Reliability test}

Not all response questions were related, and reliability tests were carried out independently for only related data cases. Response questions 1, 2 and 3 in Fig. 2(A), 2(B), 2(C) respectively are demographic in nature with no reliability tests required. Response question 16 in Fig. 2(P) is dichotomous therefore the author excluded it from the reliability analysis due to its independence from the rest of the questions. Questions shown in Table II investigating the general perception and satisfaction while using $2 \mathrm{D}$ for clash detection, visualization and understanding of design were tested for reliability since they were related to each other and Cronbach's test value of 0.71 was achieved.
Table II Reliability test value for the related data cases from Questions in Fig. 2(D-J, L-M)

\begin{tabular}{|l|l|}
\hline $\begin{array}{l}\text { Reliability Statistics } \\
\text { Cronbach's Alpha }\end{array}$ & Number of items \\
\hline 0.710 & 9 \\
\hline
\end{tabular}

For the remaining questions regarding effectiveness of BIM and AR, implementation challenges and limitations i.e. questions in Fig. 2(N-O), (Q-W), no correlations were defined from the data analyzed in these sections. While some of them were indirectly investigating similar aspects, the responses were not meant to be correlated in any way. Cronbach alpha evidently gave values below 0.5 for these cases. This was intended by the researcher as those response questions were tailored independently using the Likert scale to achieve a less biased answer which did not depend on any other choice taken in the survey. Such data was believed to produce more meaningful results for the issues in context.

The next section presents the summarized results from the descriptive statistical analysis of the data collected.

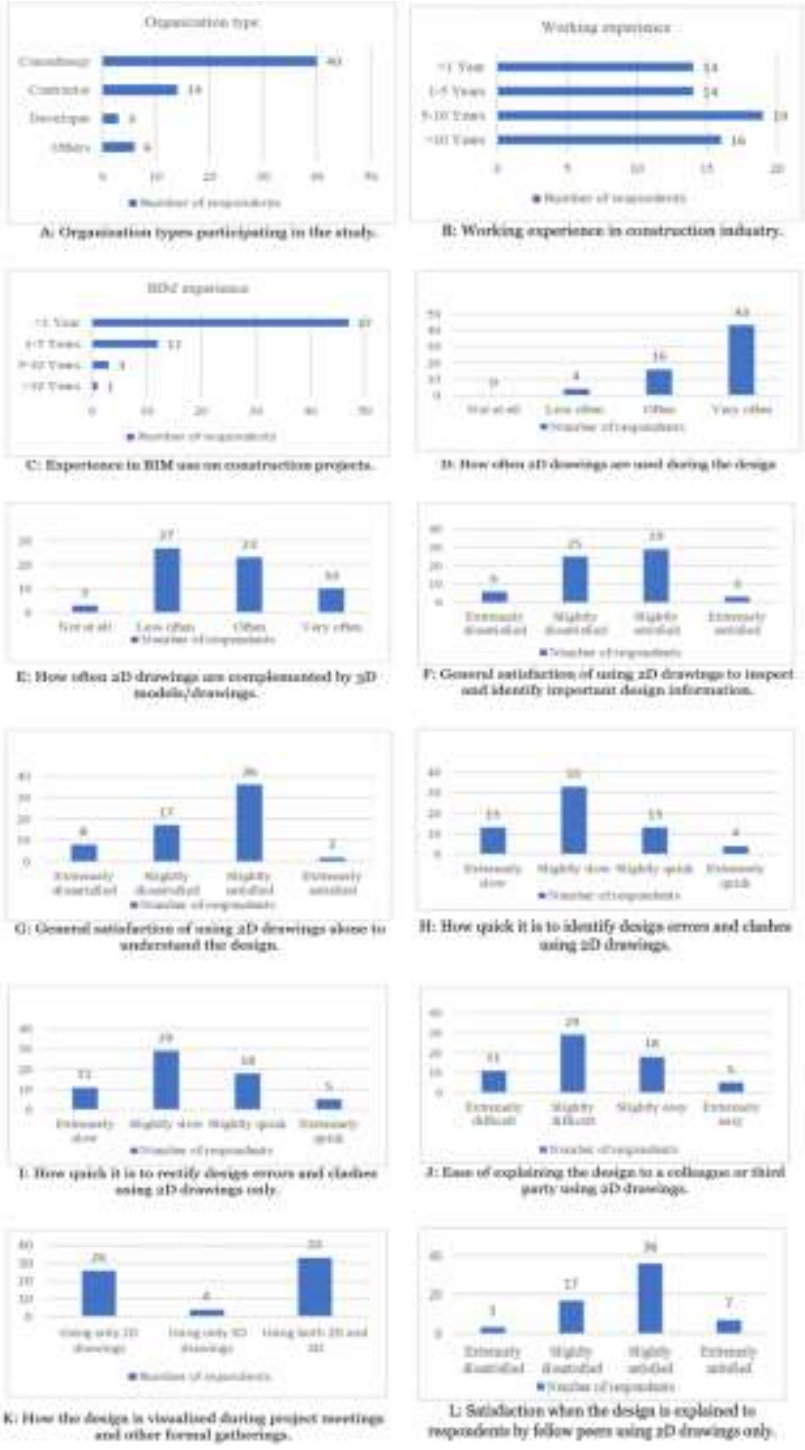

Figure 2: Statistical results from survey questionnaire responses. 


\section{Descriptive statistical analysis results}

1) Part B: Comparison of conventional 2-D workflows with $A R$ and BIM(CDE) workflows.

The criteria of assessment for this section is based solely on the 63 respondent's experience with the use of 2D drawings, $3 \mathrm{D}$ models and often a combination of both.

The results from Fig. 2(D) show that 2D drawings are frequently utilized by majority of the respondents but rarely complemented with 3D models as in Fig. 3(D). However, it is also evident in Fig. 2(K) that adoption of 3D-model driven processes is growing as justified by 33 of the respondents using both $2 \mathrm{D}$ drawings and $3 \mathrm{D}$ models during project meetings, 23 companies admitted to using only $2 \mathrm{D}$ drawings and only 4 using 3D models only.

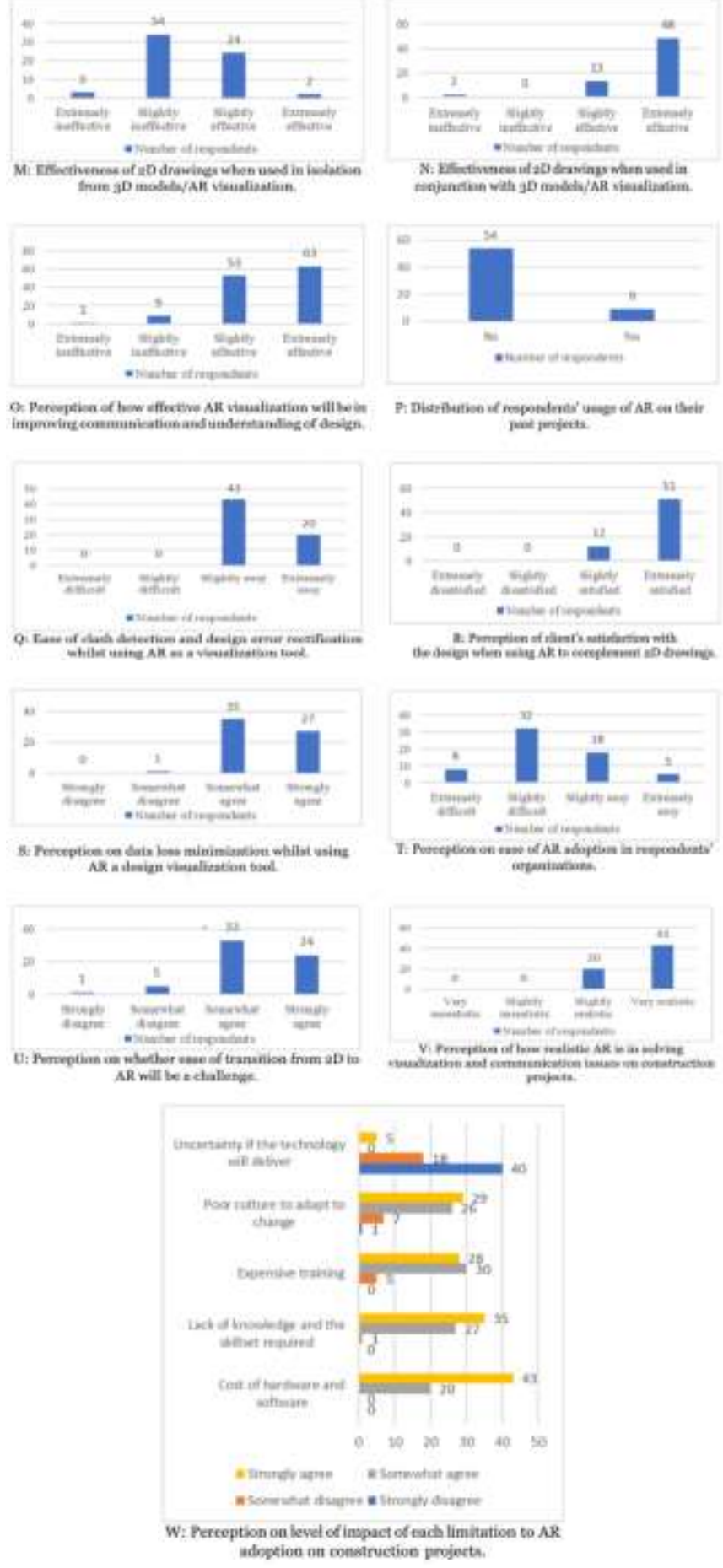

Figure 2 Continued: Statistical results from survey questionnaire responses.
The results from Fig. 2(F-G) reveal surprising levels of satisfaction with the conventional 2D workflow with 32 satisfied and 31 dissatisfied with abstracting design information while using 2D drawings only as in Fig. 2(F), this is further supplemented by Fig 2(G) showing 38 satisfied and 25 dissatisfied with using only 2D drawings to understand the design. Majority of the respondents in Fig. 2(H) and 2(I) find it hard to identify and rectify design errors with the use of $2 \mathrm{D}$ drawings alone. It is interesting to note that these results in Fig. 2(H) and 2(I) contradict with those in Fig. 2(F) and 2(G) which anomaly is discussed later. More than half (63\%) of the respondents, in Fig. 2(J) find peer to peer communications difficult while using 2D drawings in isolation specifically while explaining the design to a colleague and RFIs with only $37 \%$ satisfied. The results here again contradict with those in Fig. 2(L) which show majority of the respondents $(68 \%)$ satisfied when the design is explained to them using 2D drawings only.

From Fig. 2(M) and 2(N) more than half of the respondents, agree that $2 \mathrm{D}$ drawings become more effective when complimented with 3D models and AR tools. However, since the demographic study validated very low BIM exposure in the Malaysian construction industry as in Fig. 2(C), it is not surprising that more than $85 \%$ have never used AR in their projects, see Fig. 2(P).

Basing solely on respondent's past experience, majority agree that if AR was utilized with $2 \mathrm{D}$ drawings on their previous projects, clash detection and error rectification would have been easier and improvements in client satisfaction with the design as in Fig. 2(N-S).

The next section below presents results that assess stakeholder perception towards adoption of this technology.

\section{2) Part $C$ and D: Perception on ease of transition to $C D E$ workflows and AR adoption challenges.}

Majority of the surveyed construction key players perceive that implementing $A R$ in their organizations would be a challenge as seen in Fig. 2(T). From the open-ended survey responses, a delineation of several adoption challenges was laid out by the respondents with emphasis on resistance to change, 2D dependence, lack of proper implementation guidelines and expensive training. The results show that majority of the construction industry in Malaysia is working outside a CDE with conventional 2D approaches that don't favor usage of AR.

\section{DISCUSSION}

Sustainable design processes involve a lot of stakeholder decisions that are iterative, repetitive and often heuristic in nature. These decisions are mainly driven by two needs i.e. reducing building construction resources and optimizing the energy performance of the building during operation [17]. The former need is largely controlled by the designers and engineers whereas the latter mainly depends on the operational behavior of occupants however, the design of a building can have major impact on its subsequent energy use; a building design with poor indoor envelope characteristics will require more air conditioning during its lifespan.

While the eventual building is three dimensional, the building data that informs designers' decisions and actions still remains trapped in 2D papers which is evidently validated by the 
results presented in Fig. 2(F-H). This 2D workflow is characterized by working in isolation where the generated building data is trapped in silos with unending requests for information (RFIs) due to the poor communication and collaboration channels (Fig. 2(J)), data loss along the project flow path (Fig. 2(S)) and undetectable design errors and clashes that end up in construction (Fig. 2(H-I)). It is with no doubt that these challenges translate into unsustainable building designs which are characterized by escalated building material requirements with large carbon footprints, the design errors translate into costly demolition and rebuilding practices and poor collaboration inhibits effective stakeholder decision making during the optimization of a building design. Availability of linked building data in a 3D model creates a CDE that positively changes the way building information is generated, propagated and used along the project lifecycle. A CDE utilizes BIM to generate rich but most importantly linked building information which paves way for technologies like AR visualization that bridges the existing gap between the real and digital worlds of construction processes [22].

From the presented results, this gap is evidently the main reason why majority of the construction industry in Malaysia is stuck in the inefficiency loop of endless undetectable design errors as in Fig. 2(H-I), limited prototyping capabilities, frequent RFIs (Fig. 2(J)), poor stakeholder collaboration, large carbon footprints and poor energy efficiency of the eventual buildings. $\mathrm{CDE}$ and $\mathrm{AR}$ approaches still have continued resistance from the industry mainly due to lack of expertise in 3D modelling, poor culture to embrace change, comfortability with 2D workflows fear of investment in the unknown and lack of implementation guidelines. The contradictory anomalies presented in both Fig. 2(F-I) and Fig. $2(\mathrm{~J} \& \mathrm{~L})$ are explained by stakeholder comfortability with the familiar workflows of using 2D only and resistance to change with fear of venturing into the unknown territory. It is however promising that stakeholder perception towards adoption of these improved processes is positive and can be accelerated by guidance and support from top level management in their organizations, government implementation guidelines and funding for pilot projects that the rest of the industry can embrace and learn from [15],[23],[22].

\section{CONCLUSION}

Sustainable construction is not as straightforward as solely optimizing a building design to achieve a set of sustainable goals. The processes involved should be assumed to be heuristic, iterative, repetitive and mutually dependent to realize benefits i.e. a sustainable building design can be energy efficient today but might not stay the same during its continued lifespan due to changes in operational behavior, systems maintenance culture, facility management approaches, variable weather patterns and other environmental characteristics, however, information about all these aspects can be collected and intuitively used as input data for future building optimization processes and improvement of existing buildings. This cycle is continuous (iterative) and delivering improvement all the time from past experiences (heuristic). Benefiting from this cycle is inhibited if construction key players don't adopt LBD and CDE approaches. However, with LBD comes the need to visualize this BIG data effectively during decision making and this is how AR comes into the overall sustainability equation.

\section{REFERENCES}

1. I. E. Sutherland, "A head-mounted three-dimensional display," FJCC, vol 33, pp 757-764, 1969.

2. H. Bae, F. Golparvar, J. White, "Enhanced HD4AR (Hybrid 4- Dimensional Augmented Reality) for Ubiquitous Context-aware AEC/FM Applications," Vis. in Eng., vol 1, no. 3, pp 253-26, 2013.

3. V. Kamat, A. H. Behzadan, "Integrated information modeling and visual simulation of engineering operations using dynamic augmented reality scene graphs," Electron, J. Inf. Technol. Constr., vol 16, 259-278, 2011.

4. Autodesk, "The Inefficiency Problem - Cracking the code for AEC business success," Autodesk Inc, 2017, pp $1-18,2017$.

5. A. Pękala, I. Czmoch, "Traditional design versus BIM based design," Procedia Eng., vol 91, pp. 210- 215, 2014.

6. S. K. Jusuf, B. Mousseau, G. Godfroid, V. S. J. Hui, "Integrated modeling of CityGML and IFC for city/neighborhood development for urban microclimates analysis," Energy Procedia, vol 122, pp 145-150, 2017.

7. R. Eadie, M. Browne, H. Odeyinka, C. McKeown, S. McNiff, "BIM implementation throughout the UK construction project lifecycle: An analysis," Autom. Constr, vol 36, pp 145-151, 2013.

8. P. Dunston, D. H. Shin, "Identification of application areas for Augmented Reality in industrial construction based on technology suitability", Autom. Constr, vol 17, pp 882-894, 2008.

9. P. S. Dunston, X. Wang, "Mixed Reality-Based Visualization Interfaces for Architecture, Engineering, and Construction Industry,” J. Constr. Eng. Manag, vol 131, pp 1301-1309, 2005.

10. X. Wang, P. S. Dunston, "Strategies and issues towards an Augmented Reality-based construction training platform," Electron, J. Inf. Technol. Constr., vol 12 pp 363-380, 2007.

11. S. Savarese, G. F. Mani, "4-dimensional augmented reality model for automating construction progress monitoring data collection, processing and communication," Electron, J. Inf. Technol. Constr, vol 14, pp 129-153, 2009.

12. M. L. Waugh, B. Rausch, T. Engram, F. Aziz, "Inuvik Super School VR Documentation: Mid-Project Status,' vol 30, pp 221-230, 2012.

13. C. S. Park, D. Y. Lee, O. S. Kwon, X. Wang, "A framework for proactive construction defect management using BIM, augmented reality and ontology-based data collection template," Autom. Constr., vol 33, pp 61-71, 2013.

14. A. Kiviniemi, "Experiences from the BIM-Adoption in Finland and UK - Clients as the drivers of innovation", Univ. of Liv., pp 1-45, 2016.

15. A. A. Latiffi, S. Mohd, U. 
S. Rakiman, "Potential improvement of building information modeling (BIM) Implementation in Malaysian construction projects," IFIP Adv, Inf. Commun. Technol, vol 446, pp 149-158, 2016.

16. S. Musa, A. P. Marshall, F. A. A. Nifa, S. A. Sharon, "BIM in Malaysian Construction industry", AIP conference proceedings, vol 2016, pp 20-105, 2018

17. S. Smith, "Will augmented reality in construction deliver on its promise," ICE, 2016.

18. R. Spence and H. Mulligan, "Sustainable development and the construction industry," Habitat Int., vol. 19, no. 3, pp. 279-292, 1995.

19. A. Borrmann, M. König, C. Koch, and J. Beetz, "Building Information Modeling Technology Foundations and Industry Practice" pp 181-194, 2018.

20. P. Pauwels, M. Kris, T. Seppo, and B. Jakob, "Linked Data," pp. 181-186, 2018.

21. Autodesk, "Building Information Modeling-White Paper" Autodesk Inc, pp 1-6, 2003.

22. C. Eastman, P. Teicholz, R. Sacks, \& K. Liston, "BIM handbook: A guide to building information modeling for owners, managers, designers, engineers and contractors," Hoboken: John Wiley \& Sons, 2008.

23. A. Azzouz, \& P. Hill, "Hunting for perfection: How Arup measures BIM maturity on projects worldwide," Construction Research and Innovation vol 8 no. 2, pp 49-54, 2016.

24. WRI, "World Resources 1992-93: A Report by the World Resources Institute," Oxford University Press, 1992. 